\title{
Importance of Vitamin D in Dogs Fed Homemade Diet: A Brief and Systematic Review
}

\author{
Prenal Y. Badwaik ${ }^{*}$, Md. Javed Ashar ${ }^{2}$ and Gautam R. Bhojne ${ }^{1}$ \\ ${ }^{1}$ Department of Veterinary Clinical Medicine, Ethics and Jurisprudence, Nagpur Veterinary \\ College, Nagpur-440006, Maharashtra, India \\ ${ }^{2}$ Department of Animal Nutrition, KNP College of Veterinary Science, Shirwal-412801, \\ Maharashtra, India \\ *Corresponding author
}

\begin{tabular}{l} 
Ke y w o r d s \\
Vitamin D, \\
Cholecalciferol, \\
Dog, India, \\
1,25(OH)2D \\
\hline Article Info \\
$\begin{array}{l}\text { Accepted: } \\
20 \text { October } 2020 \\
\text { Available Online: } \\
10 \text { November } 2020\end{array}$
\end{tabular}

A B S T R A C T
Vitamin D, a steroid also classified as a hormone is well known for its crucial role in bone health through calcium-phosphorus metabolism. Over time, after enormous studies, researchers have successfully established that vitamin $\mathrm{D}$ deficiency is associated with increased risk of disease conditions like cancer, diabetes, cardiovascular diseases, hypertension, infectious diseases etc. in humans. Similarly, veterinary studies carried out in dogs found Vitamin D deficiency associated with increased risk of pathological conditions; thereby interfering with good quality of life in dogs. Unlike humans, dogs entirely depend on their diet to fulfil their Vitamin D requirements due to inadequate cutaneous synthesis of Vitamin D. This paper documents the sources, metabolism, various non-bone related roles of Vitamin D, its serum concentrations, and the recommended levels in a diet from the available publications in view to put emphasis on the necessity to improve Vitamin D status of dogs in India, who are being fed homemade diet.

\section{Introduction}

In 1918 Mellanby identified the "Accessory factor" by curing rachitic puppies with a therapeutic dose of cod-liver oil, that accessory factor is Vitamin $\mathrm{D}$ (How et al., 1995). Vitamin D includes, cholecalciferol
(Vitamin D3) of animal origin and ergocalciferol (Vitamin D2) of a plant origin. Vitamin D metabolites are of great importance in calcium metabolism, regulating its active intestinal absorption, renal regulation, and its deposition in and mobilization from the skeleton (How et al., 
1994). In dogs along with the key role in skeletal development and maintenance through calcium metabolism, studies found other significant functions of vitamin D associated with other than bone which ultimately helps to improve dog's health. This paper throws light on the vital roles of vitamin $\mathrm{D}$ considering the homemade diet given to dogs in India very often.

\section{Metabolism of vitamin D}

There are two dietary forms of vitamin D: cholecalciferol (vitamin D3), which normally comes from animal food sources, and ergocalciferol (vitamin D2), which naturally comes from plant sources. Cats may not utilize ergocalciferol as efficiently as cholecalciferol; however, dogs have the ability to utilize both dietary forms equally(Parker et al., 2017).

In various species, including sheep, cattle, horses, pigs, rats, and man, that after exposure to an adequate amount of ultraviolet (UV) light in the B-range $(290-320 \mathrm{~nm})$ photolysis of 7 dehydrocholesterol (7DHC) to previtamin $\mathrm{D}$ takes place in the epidermis; Previtamin $\mathrm{D}$ can isomerize into vitamin $\mathrm{D}$, influenced by the temperature and the presence of cellular lipids and proteins of the skin (How et al., 1995). The newly formed vitamin D and the vitamin D supplied through diet is transported by vitamin $\mathrm{D}$ binding proteins to the liver (How et al., 1995; Parker et al., 2017). In the liver, it is hydroxylated by 25-hydroxylase to form 25(OH)D (also known as calcidiol or calcifediol) (Parker et al., 2017). Then, 25(OH)D is hydroxylated via $1 \alpha$-hydroxylase to form $1,25(\mathrm{OH}) 2 \mathrm{D}$, this activation of $1,25(\mathrm{OH}) 2 \mathrm{D}$ occurs predominately in the kidneys; however, it also occurs in other tissues that express $1 \alpha-$ hydroxylase (Parker et al., 2017). Finally, $1,25(\mathrm{OH}) 2 \mathrm{D}$ affects many target cells via a vitamin D receptor-mediated mechanism;
$1,25(\mathrm{OH}) 2 \mathrm{D}$ is the most active naturally occurring vitamin D metabolite; also known as calcitriol (Parker et al., 2017). Depending on the vitamin D status, cholecalciferol can be stored in the body, especially in the adipose tissue; however, a small portion (approximately 16\%) can be found in muscle tissue (Zafalon et al., 2020).

But in dogs, How et al., (1994) found very low concentrations of the 7dehydrocholesterol present in the skin and that showed minimal UV-mediated conversion to vitamin $\mathrm{D}$, especially when compared to conversion rates in rat skin (Weidner and Verbrugghe, 2017). Therefore Dogs are fully dependent on their dietary intake of vitamin D3 since they are not able to synthesize vitamin D3 in their skin under the influence of ultraviolet light/sunlight (Hazewinkel and Tryfonidou, 2002).

There are congenital abnormalities caused by genetic mutations that have an impact on vitamin $\mathrm{D}$ metabolism. Two autosomal recessive genetic defects have been identified in humans: vitamin D type I-dependent rickets (VDDR-I) and vitamin D type IIdependent rickets (VDDR-II), both have also been reported in dogs and cats (Zafalon et al., 2020).

\section{Vitamin D status}

Serum 25(OH)D concentrations have been generally accepted as a marker of vitamin D status, as $25(\mathrm{OH}) \mathrm{D}$ is one of the most stable metabolites of vitamin $\mathrm{D}$, reflective of vitamin $\mathrm{D}$ obtained from the diet and skin production with a half-life estimated to range from 10 days to 3 weeks as compared to 1,25(OH)2D has a short half-life of 4-6 hours (Weidner and Verbrugghe, 2017). Besides, the measurement of calcitriol is very intricate because of its hydrophobic nature and very low concentrations in the blood (in 
picomolar) that is about 1,000 times lower than the circulating concentrations of 25(OH)D (Zafalon et al., 2020).

A study, define sufficiency of $25(\mathrm{OH}) \mathrm{D}$ through the use of iPTH, c-CRP, and phosphorus as biomarker along with the relative risk of cancer, and based on results, suggest that a target range of 100-120 ngmL-1 be used for establishing $25(\mathrm{OH}) \mathrm{D}$ sufficiency in dogs; they also suggest that, most dogs with sufficient vitamin $D$ had concentrations in the range of 100-150 ngmL-1, thus toxicity most likely occurs above these levels (Selting et al., 2016).

\section{Sources of vitamin $D$ and dietary recommendation}

The D vitamins are limited in distribution. Rich sources of Vitamin D include Halibutliver and cod-liver oils; Egg yolk is also a good source, but cow's milk being an indigent source of Vitamin D, though summer milk tends to be comparatively richer than winter milk (McDonald, 2011, p.79). Indian fishes rich in Vitamin D include Amblypharyngodon mola, Puntius sophore, Epinephelus spp (Mohanty et al., 2016).

\section{Dietary recommendations of Vitamin D (Table 1 and 2)}

Although, the currently recommended allowances by NRC are based on the nonoccurrence of bone abnormalities in puppies. However, the Vitamin D requirement for adult dogs has not been established (Young and Backus, 2017; Zafalon et al., 2020). A study conducted by Young and Backus, on the oral Vitamin D supplementation at five times the NRC recommended allowance within the safe upper limit over a period of 910 weeks corroborated that oral Vitamin D3 helped increase the serum 25(OH)D concentrations but not sufficient to reach the target range of $100 \mathrm{ng} / \mathrm{ml}$ as previously suggested for Vitamin D sufficiency in healthy, adult dogs.

\section{Role of vitamin D}

In human, after lots of research, studies have found that there are correlations between insufficient levels of vitamin D and increased risk of developing non-skeletal pathologies such as cardiovascular diseases, hypertension, cancer, diabetes, multiple sclerosis, rheumatoid arthritis, infectious diseases, and asthma (Selting et al., 2016). Likewise In veterinary, research is going on to find a similar link between vitamin D deficiency and their associated risk in dogs. Through continuous efforts, researchers found that vitamin $\mathrm{D}$ plays very important roles in improving dog's health as well.

Rickets a historically well-known metabolic bone disease typically caused by a dietary deficiency of vitamin D or phosphorus or by genetic defects affecting the metabolism of vitamin $\mathrm{D}$ or phosphorus; likewise, dogs fed unbalanced meat-based diets without vitamin D supplementation are more likely to develop fibrous osteodystrophy, rather than rickets, because of the development of nutritional hyperparathyroidism (Parker et al., 2017). Apart from this, decreasing serum 25(OH)D concentration below 40ngml-1 was found to be related with the increased relative risk of cancer, and supplementation may improve health and response to cancer therapy (Selting et al., 2016).

In heart, Cardiac myocytes possess vitamin D receptors and a calcitriol-dependent calciumbinding protein (Kraus et al., 2014), based on that researcher investigated vitamin $D$ deficiency is linked with heart conditions like low serum $25(\mathrm{OH}) \mathrm{D}$ concentration was associated with poor outcome in dogs with $\mathrm{CHF}$ hence be a risk factor for $\mathrm{CHF}$ in dogs(Kraus et al., 2014). Similarly, serum $25(\mathrm{OH}) \mathrm{D}$ concentrations were significantly 
lower in chronic valvular heart disease (CVHD) dogs in Stage B2, as well as in Stage C/D, compared with control (Stage B1) dogs, indicating that vitamin $\mathrm{D}$ status is related to the degree of cardiac remodelling (Osuga et al., 2015).

Studies also found that serum 25(OH)D concentration in dogs with an immunemediated disease (IMD) and Chronic Enteropathy (CE) was low and associated with decreased survival time and therefore can be helpful as a prognostic biomarker in dogs to provide additional prognostic information to owners and veterinarians managing these condition in dogs (Mick et al., 2019; Titmarsh et al., 2015). Further, in a retrospective study of 43 dogs, low serum $25(\mathrm{OH}) \mathrm{D}$ concentration in dogs with proteinlosing enteropathy (PLE) were found to be significantly associated with poor outcome (Allenspach et al., 2017). Moreover vitamin D metabolites, calcidiol and calcitriol modulate cell growth, neuromuscular and immune function, and reduces inflammation as well (Sharp et al., 2015).

However many roles of vitamin D is still not known in dogs, which have been linked to vitamin D deficiency in human, further research on Vitamin D and its metabolites in dogs will help to connect various conditions associated with Vitamin D deficiency.

\section{Table.1 The Vitamin D recommendations as provided by AAFCO (The Association of American Feed Control Officials) are:-}

\begin{tabular}{|c|c|c|c|}
\hline $\begin{array}{c}\text { Nutrient (\% or per } \\
\text { kg of diet) }\end{array}$ & $\begin{array}{c}\text { Growth and } \\
\text { Reproduction } \\
\text { Minimum }\end{array}$ & $\begin{array}{c}\text { Adult maintenance } \\
\text { Minimum }\end{array}$ & $\begin{array}{c}\text { Adult maintenance } \\
\text { Maximum }\end{array}$ \\
\hline Vitamin D (IU/kg) & 500 & 500 & 5000 \\
\hline
\end{tabular}

Source:(Nutritional Requirements and Related Diseases of Small Animals - Management and Nutrition - Veterinary Manual, n.d.)

Table.2 The Vitamin D recommendations as laid by 2006 NRC (National Research Council)for Puppies after Weaning and Adult dogs (Maintenance) are:-

\begin{tabular}{|c|c|c|c|}
\hline $\begin{array}{c}\text { Nutrient } \\
\text { (amount/1000 kcal } \\
\text { of ME) }\end{array}$ & Minimum & Maximum & $\begin{array}{c}\text { Recommended } \\
\text { allowance }\end{array}$ \\
\hline $\begin{array}{c}\text { Cholecalciferol } \\
(\mathrm{mcg})\end{array}$ & & 20 & 3.4 \\
\hline
\end{tabular}

Source:(Nutritional Requirements and Related Diseases of Small Animals - Management and Nutrition - Veterinary Manual, n.d.)

As dogs solely depend on the dietary sources of vitamin $\mathrm{D}$, therefore it can be considered as an essential constituent of canine diet, and requiring a regular dietary intake irrespective of the season (How et al., 1995). Since vitamin $\mathrm{D}$ is present only in a few dietary sources, homemade diets are often deficient according to NRC, AAFCO, and FEDIAF (European Pet Food Industry Federation) standards (Weidner and Verbrugghe, 2017). As far as the Indian pet parents are concerned, most of them feed their dogs a homemade diet, most of which includes chapatti, rice and milk. Besides, some pet parents feed their 
dogs bread crumbs, toasted bread and occasionally commercial pet food and some, depending on their financial condition and religious orientation go for boiled chicken and chevon. Considering the homemade feeds offered to Indian dogs, it can be said that many dogs in such conditions are inclined to Vitamin D insufficiency.

The NRC recommendations of Vitamin D in dogs have been made concerning the prevention of bone abnormalities. There are no recommendations on the amount of Vitamin D required for functions other than bone metabolism regulation. Since this data is not available, it needs to be ensured that canines receiving homemade diets have an optimum level of vitamin D supplements in their diet. Good natural sources of vitamin D that can be added to homemade diets include egg yolk and fish. Boiled egg yolk as a vitamin $\mathrm{D}$ supplement can be used by many Indian households as it is easily available, financially feasible, and conventionally consumed. A 17-gram chicken egg yolk has 37.1 IU of Vitamin D (Food Data Central, n.d.). As eggs are considered nutrient-dense food, feeding a whole boiled egg a day may help in reducing the chances of Vitamin D deficiency. Similarly, fish meat is an excellent source of vitamin D in which Pool barb (Puntius sophore) and Mola carplet (Amblypharyngodon mola) have 16,266.4 \pm 84.213 IU vitamin D per $100 \mathrm{gm}$. of wet weight and 93,122.4 $\pm 89.26 \mathrm{IU}$ vitamin D per $100 \mathrm{gm}$. of wet weight respectively(Mohanty et al., 2016). However, the most commonly available fishes such as the Indian oil sardine (Sardinella Longiceps), Catla (Catlacatla), Rohu (Labeorohita), Walking catfish (Clariasbatrachus) locally known as Magur, carry 21,288.0 $\pm 25.3,59.5 \pm 12.58,84.4 \pm$ 11.2 and $30.9 \pm 10.2$ IU of Vitamin D per $100 \mathrm{gm}$. of wet weight(Mohanty et al., 2016). Introducing a whole, cleaned, and properly cooked fish meat to canine diet once a day or in alternate days or at least twice a week depending on their Vitamin D concentrations may be useful. People living in coastal areas in India can easily get fish to supplement the canine diet. Furthermore, various commercially available Vitamin D supplements such as cod liver oil, cholecalciferol in the form of syrup, granules, or tablets are available which can be added in desired amounts to dogs receiving homemade diet insufficient in Vitamin D.

Commercially available balanced foods following AAFCO, FEDIAF, or NRC recommendations carry decent amounts of Vitamin D. Since all pet owners cannot afford commercial food for their dogs, they can incorporate Vitamin D rich food items or supplements. Educating the owner about the importance of vitamin D and advising quality sources of vitamin D depending on the situation, availability, and economic status of the owner can help to improve health in terms of Vitamin D status.

With the upcoming advances in research and technology, various physiological functions of Vitamin D are being discovered in canines. However, the amount of Vitamin D to be fed to meet such requirements and the normal serum concentrations of Vitamin D necessary to carry out these roles have not been defined so far. Further detailed studies and investigations are needed to be carried out to outline the requirements of Vitamin D.

\section{References}

Allenspach, K., Rizzo, J., Jergens, A. E., and Chang, Y. M. (2017). Hypovitaminosis $\mathrm{D}$ is associated with negative outcome in dogs with protein losing enteropathy: A retrospective study of 43 cases. BMC Veterinary Research, 13(1), 1-6. https://doi.org/10.1186/s12917-0171022-7 
Hazewinkel, H. A. W., and Tryfonidou, M. A. (2002). Vitamin D3 metabolism in dogs. Molecular and Cellular Endocrinology, 197(1-2), 23-33. https://doi.org/10.1016/S03037207(02)00275-7

How, K. L., Hazewinkel, H. A., and Mol, J. A. (1995). Photosynthesis of vitamin D in the skin of dogs cats and rats. The Veterinary Quarterly, 17 Suppl l(October 2014), 29. https://doi.org/10.1080/01652176.1995. 9694579

How, K. L., Hazewinkel, H. A. W., and Mol, J. A. (1994). Dietary vitamin D dependence of cat and dog due to inadequate cutaneous synthesis of vitamin D. General and Comparative Endocrinology, 96(1), 12-18. https://doi.org/10.1006/gcen.1994.1154

Kraus, M. S., Rassnick, K. M., Wakshlag, J. J., Gelzer, A. R. M., Waxman, A. S., Struble, A. M., and Refsal, K. (2014). Relation of Vitamin D status to congestive heart failure and cardiovascular events in dogs. Journal of Veterinary Internal Medicine, 28(1), 109-115.

https://doi.org/10.1111/jvim.12239

McDonald, P. (2011). Animal Nutrition (7th ed). Harlow, England; New York: Prentice Hall/Pearson, 2011.

Mick, P., Peng, S., and Loftus, J. (2019). Serum Vitamin D Metabolites and CXCL10 Concentrations Associate With Survival in Dogs With Immune Mediated Disease. Frontiers in Veterinary Science, 6. https://doi.org/10.3389/fvets.2019.0024 7

Mohanty, B. P., Sankar, T. V., Ganguly, S., Mahanty, A., Anandan, R., Chakraborty, K., Paul, B. N., Sarma, D., Dayal, J. S., Mathew, S., Asha, K. K., Mitra, T., Karunakaran, D., Chanda, S., Shahi, N., Das, P., Das, P., Akhtar, M.
S., Vijayagopal, P., and Sridhar, N. (2016). Micronutrient Composition of 35 Food Fishes from India and Their Significance in Human Nutrition. Biological Trace Element Research, 174(2), 448-458.

https://doi.org/10.1007/s12011-0160714-3

Nutritional Requirements and Related Diseases of Small Animals Management and Nutrition - Veterinary Manual. (n.d.).

Osuga, T., Nakamura, K., Morita, T., Lim, S. Y., Nisa, K., Yokoyama, N., Sasaki, N., Morishita, K., Ohta, H., and Takiguchi, M. (2015). Vitamin D Status in Different Stages of Disease Severity in Dogs with Chronic Valvular Heart Disease. Journal of Veterinary Internal Medicine, 29(6), 1518-1523. https://doi.org/10.1111/jvim.13606

Parker, V. J., Rudinsky, A. J., and Chew, D. J. (2017). Vitamin D Metabolism and Hormonal Influences Vitamin D metabolism in canine and feline medicine Vitamin D Roles. Journal of the American Veterinary Medical Association, 250(11).

Selting, K. A., Sharp, C. R., Ringold, R., Thamm, D. H., and Backus, R. (2016). Serum 25-hydroxyvitamin D concentrations in dogs - correlation with health and cancer risk. Veterinary and Comparative Oncology, 14(3), 295-305.

https://doi.org/10.1111/vco.12101

Sharp, C. R., Selting, K. A., and Ringold, R. (2015). The effect of diet on serum 25hydroxyvitamin $\mathrm{D}$ concentrations in dogs Veterinary Research. $B M C$ Research Notes, 8(1), 4-9. https://doi.org/10.1186/s13104-0151360-0

Titmarsh, H., Gow, A. G., Kilpatrick, S., Sinclair, J., Hill, T., Milne, E., Philbey, A., Berry, J., Handel, I., and Mellanby, 
R. J. (2015). Association of Vitamin D Status and Clinical Outcome in Dogs with a Chronic Enteropathy. Journal of Veterinary Internal Medicine, 29(6), 1473-1478.

https://doi.org/10.1111/jvim.13603

Weidner, N., and Verbrugghe, A. (2017). Current knowledge of vitamin D in dogs. Critical Reviews in Food Science and Nutrition, 57(18), 3850-3859. https://doi.org/10.1080/10408398.2016. 1171202
Journal of nutritional science. 1-9. https://doi.org/10.1017/jns.2016.23

Zafalon, R. V. A., Risolia, L. W., Pedrinelli, V., Vendramini, T. H. A., Rodrigues, R. B. A., Amaral, A. R., Kogika, M. M., and Brunetto, M. A. (2020). Vitamin D metabolism in dogs and cats and its relation to diseases not associated with bone metabolism. Journal of Animal Physiology and Animal Nutrition, 104(1), 322-342. https://doi.org/ 10.1111/jpn.13259.

Young, L. R., and Backus, R. C. (2017).

\section{How to cite this article:}

Prenal Y. Badwaik, Md. Javed Ashar and Gautam R. Bhojne. 2020. Importance of Vitamin D in Dogs Fed Homemade Diet: A Brief and Systematic Review. Int.J.Curr.Microbiol.App.Sci. 9(11): 2562-2568. doi: https://doi.org/10.20546/ijcmas.2020.911.310 